\title{
Ultrasonographic Monitoring of Nuclear Transferred Fetal Weight during the Final Stage of Gestation in Holstein Cows
}

\author{
Masahiro TAKAHASHI ${ }^{1)}$, Taichi GOTO ${ }^{1) *}$, Hideki TSUCHIYA ${ }^{2)}$, Atushi UEKI ${ }^{1)}$ and Kyoko KAWAHATA ${ }^{1)}$ \\ ${ }^{1)}$ Technical Research Center, Koiwai Noboku Co., Ltd., Shizukuishi, Iwate 020-0507 and 2)Animal Bio-Technology Center, Livestock \\ Improvement Association of Japan, Inc., Shinagawa, Tokyo 140-0002, Japan
}

(Received 11 September 2003/Accepted 9 May 2005)

ABSTRACT. Dystocia or stillbirth accompanied by Large Offspring Syndrome (LOS) occurs rather frequently in Holstein nuclear transferred calves. In regard to prophylaxes, nuclear transferred Holstein fetuses were monitored with ultrasonography during the final stage of gestation. Fetal weight was estimated weekly based on the fetal metacarpal width using ultrasonography. Fourteen Holstein cows pregnant with Holstein nuclear transferred fetuses were the subjects of this experiment. The fetal weight was estimated by measuring the fetal metacarpal width during the last month of gestation according to the expected date of parturition. Measurements were performed on a weekly basis. The ultrasound-estimated metacarpal width and body weight of 13 of the fetuses in the last week of gestation ( $30.2 \pm 2.2$ $\mathrm{mm}, 50.0 \pm 4.7 \mathrm{~kg})$ were similar to the actual measurement immediately after birth $(30.0 \pm 2.1 \mathrm{~mm}, 51.2 \pm 5.5 \mathrm{~kg})$. These results indicate that ultrasonographic monitoring within a week of parturition to is accurate for estimating fetal weight. Prediction of LOS with ultrasonography contributes to reliable a diagnostic method that minimizes syndrome-related gyneco-obstetric complications at parturition with the aid of appropriate treatments.

KEY WORDS: birth weight, Holstein, metacarpal width, nuclear transfer, ultrasonography.

J. Vet. Med. Sci. 67(8): 807-811, 2005

The first nuclear transferred calf was born in 1987 [7]. Nuclear transfer technology is expected to assist in the promotion of the Japanese livestock industry. It is already being applied to genetically modified cattle that produce biopharmaceuticals in milk in the United States [1]. However, there are great losses from the parturient problems, such as dystocia and stillbirth caused by large offsprings [3, $12,13]$. We believe that the survival rate after birth would be lowered while the rate of dystocia and stillbirth would be higher in Holstein nuclear transferred calves with Large Offspring Syndrome (LOS) [9]. Therefore, monitoring the fetal weight during the final stage of gestation would be important. Positive correlations have been identified between the width of the metacarpus or metatarsus and the birth weight of Holstein calves soon after birth [10], and this might enable to anticipation of the risk of dystocia by measurement of the width of metacarpus or metatarsus before parturition.

In this study, the metacarpal width or metatarsal width of Holstein nuclear transfer fetuses were measured with ultrasonic diagnostic equipment, and these were verified to see whether birth weight or dystocia in Holstein calves could be estimated during the final stage of gestation.

\section{MATERIALS AND METHODS}

Animals: The method of producing Holstein nuclear transfer calves and the judgment of dystocia were based on data reported previously [9]. Donor nuclei originating from somatic cells for nuclear transfer embryos were derived

\footnotetext{
* Present address: Goto, T., Iwate Breeding Service, Kanegasaki, Iwate 029-4503, Japan.
}

from femoral region myocytes. Out of 1,700 cattle, including 680 dairy cows, at a farm, fourteen Holstein cows pregnant with Holstein nuclear transferred fetuses were used in the present experiment. Eleven cows received a nuclear transfer embryo using embryo cells, while the other three received a nuclear transferred embryo using somatic cells.

Ultrasonography: Fetuses were monitored once a week with an ultrasound scanner (EUB-905, Hitachi-Medical, Tokyo, Japan) with a $5 \mathrm{MHz}$ linear probe (EUP-032T, Hitachi-Medical, Tokyo, Japan) during the month of the expected date of parturition. The fetal metacarpus or metatarsus was monitored with basically the same method applied for observation of the ovarium or uterus. The diameter of the narrowest part of the fetal metacarpus or metatarsus (skin-os-skin) was measured (transverse-long axis, Fig. 1). There was no significant difference in the diameter between the dorsal and ventral positions. Both the fetal metacarpus and metatarsus were measured several times, and then the narrowest value was selected. The width $(\mathrm{mm})$ is shown if the width of the fetal metacarpus or metatarsus could be measured. An $\bigcirc$ was used to symbolize that although it was not possible to measure the width of the fetal metacarpus or metatarsus, a part of the fetal body (head, dorsum, gluteal region, or hoof) could be touched. An $\times$ was used to symbolize that it was not possible to measure the width of these fetal parts and none of the fetal body was touched. A - was used to symbolize that measurement of the fetal body was not performed (Table 1). Confirmation of the cephalic presentation was made through palpation of the fetal head, whereas posterior presentation was confirmed through palpation of the tendo Achillis.

Estimation of fetal weight: A significant correlation has been shown between the width of the metacarpus $\left(\mathrm{x}_{1} \mathrm{~mm}\right)$ or 


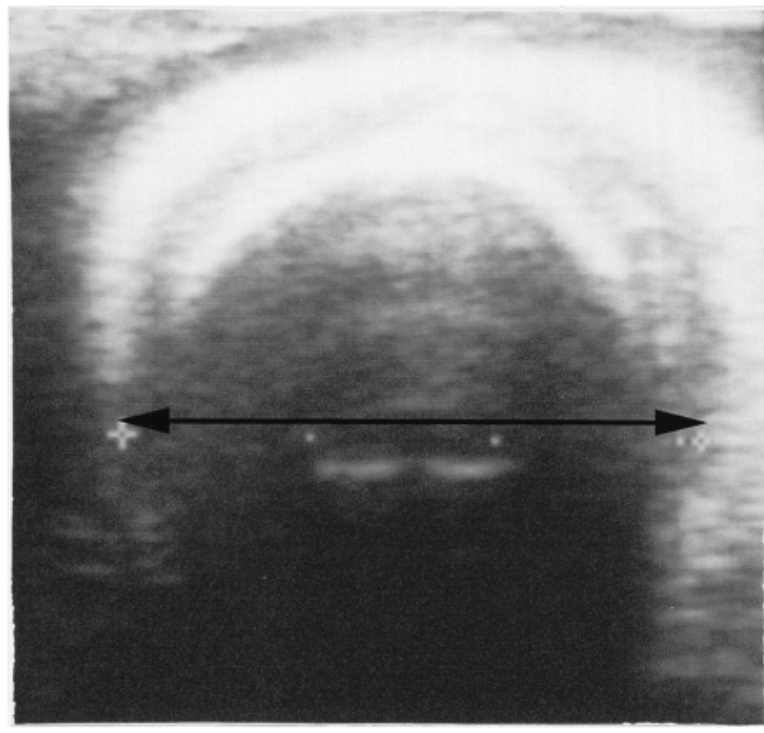

Dorsal metacarpal side

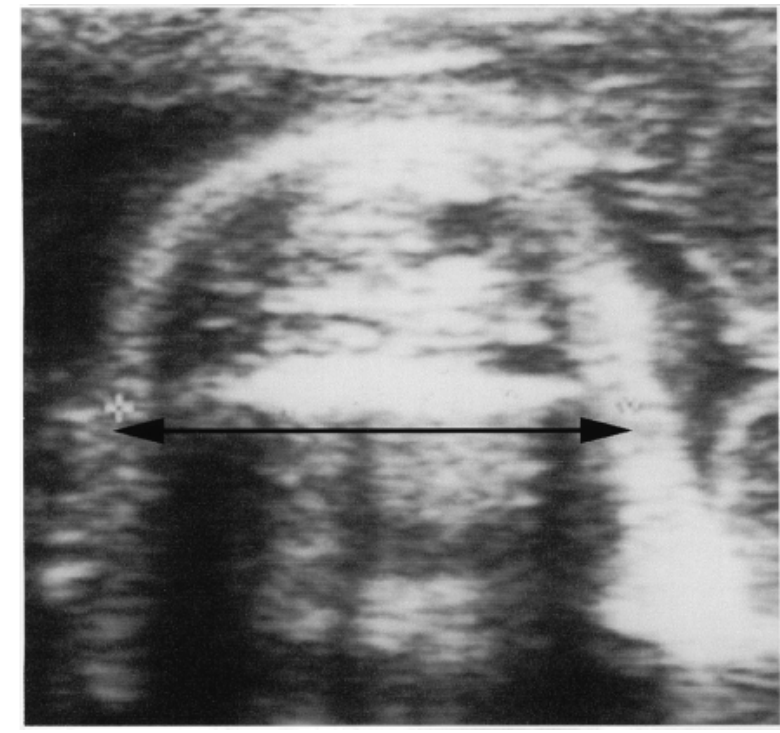

Ventral metacarpal side

Fig. 1. Ultrasonography of Holstein fetal metacarpus at the end of the gestation period. The distance represented by the arrow (skin-osskin) was measured.

metatarsus $\left(\mathrm{x}_{2} \mathrm{~mm}\right)$ and the birth weight $(\mathrm{y} \mathrm{kg})$ in Holstein calves previously [10]. In the same way, the relationship between the width of the metacarpus and the birth weight of 187 Holstein calves was reported to be $y=2.152 \mathrm{x}_{1}-15.015$, with a positive correlation coefficient of $\mathrm{r}=0.780(\mathrm{p}<0.05)$. The relationship between the width of metatarsus and the birth weight was reported to be $y=2.169 \mathrm{x}_{2}-7.204$, with a positive correlation coefficient of $r=0.684(\mathrm{p}<0.05)$. Based on these previous results, we evaluated the both fetal weight and fetal size through measurement of the width of the fetal metacarpus and metatarsus.

Obstetrical treatment: The risk of dystocia increases when the metacarpal width exceeds $30-31 \mathrm{~mm}$ [10]. So, induction of parturition or use of cesarean section was adopted for cows when the width of the fetal metacarpal exceeded $30 \mathrm{~mm}$. The induction of parturition was carried out when it was judged that there was a high possibility of dystocia based on the length of the remaining period to term and the presence of a large-continuously growing fetus. Induction was performed at random when signs of udder swelling or pelvic ligament relaxation were not apparent. An intramuscular injection of Dexamethasone $20 \mathrm{mg}$ (Recipients No. 12, 13) or PGF2 $\alpha 25 \mathrm{mg}$ (Recipient No. 2, $8,9)$ was used for this purpose.

The birth weight $(\mathrm{kg})$, the widths of metacarpus and metatarsus ( $\mathrm{mm})$, parturient difficulty, sex, and gestation period (days) were measured and recorded immediately after birth for the Holstein nuclear transfer calves. Both the width of the metacarpus and metatarsus were measured at the narrowest diameter (transverse-long axis) on the skin using calipers (Table 1). Parturient difficulty was classified based on a scale of 1-5 as follows: 1: natural parturition without assistance; 2: parturition with slight assistance; 3 : parturition in which traction by 2-3 adults was necessary; 4: parturition in which traction by many people was necessary; and 5: parturition in which veterinary surgical treatment was necessary, such as cesarean section or fetotomy.

When the fetal size was estimated by way of metacarpal width, occurrence of dystocia and parturient difficulty were classified into three subgroups (A, B, C; Table 2). Group A: induction of parturition as the fetal metacarpal width exceeds $30 \mathrm{~mm}$, Group B: natural parturition regardless of the fetal metacarpal width exceeding $30 \mathrm{~mm}$, Group C: natural parturition as the fetal metacarpal width will be less than $30 \mathrm{~mm}$.

Statistics: The metacarpal width, birth weight, gestational period, parturient difficulty for each calf was compared among the three subgroups. Data were expressed as means \pm standard deviation and analyzed by the student's $t$-test. However, data from recipients No.6 and No.14 were removed and not shown in Table 2 . We were unable to measure the fetal metacarpal width within the week prior to parturition for No.6, and No.14 failed because of parturient paralysis and was subjected to cesarean section.

\section{RESULTS}

Estimated fetal weights and their parturient conditions are shown in Table 1. Most of the fetuses ( 13 out of 14 ) had cephalic presentation detected by rectal palpation, and therefore the fetal metacarpal widths were measured. The metacarpus width was measured in every case, except for recipient No.1, at 14-8 days before parturition where the metatarsus width was also measured. There were several cases where fetal parts were slightly palpated, but the metacarpal width was not measured, and there were cases were the 
Table 1. Fetal weight estimated by fetal metacarpal width measurement prior to parturition and parturient condition of Holstein nuclear transfer calves

\begin{tabular}{|c|c|c|c|c|c|c|c|c|c|c|c|c|}
\hline \multirow{2}{*}{\multicolumn{2}{|c|}{$\begin{array}{c}\text { Recipient } \\
\text { No. }\end{array}$}} & \multicolumn{4}{|c|}{$\begin{array}{l}\text { Fetal metacarpal width }(\mathrm{mm}) \\
\text { (Estimated fetal weight, } \mathrm{kg} \text { ) }\end{array}$} & \multirow[t]{3}{*}{$\begin{array}{l}\text { Calf metacarpal } \\
\text { width }(\mathrm{mm})\end{array}$} & \multirow{3}{*}{$\begin{array}{c}\text { Birth } \\
\text { weight } \\
(\mathrm{kg})\end{array}$} & \multirow{3}{*}{$\begin{array}{c}\text { Gestation } \\
\text { period } \\
\text { (Days) }\end{array}$} & \multirow[t]{3}{*}{$\begin{array}{l}\text { Parturient } \\
\text { difficulty }\end{array}$} & \multirow[t]{3}{*}{ Sex } & \multirow[t]{3}{*}{$\begin{array}{r}\text { Calf metatars } \\
\text { width }(\mathrm{mm})\end{array}$} & \multirow[t]{3}{*}{ Notes } \\
\hline & & \multicolumn{4}{|c|}{ Days before the parturition } & & & & & & & \\
\hline & $35-29$ & $28-22$ & $21-15$ & $14-8$ & $7-1$ & & & & & & & \\
\hline \multicolumn{13}{|c|}{ (Nuclear transfer calves derived from embryo cells) } \\
\hline 1 & - & $\begin{array}{c}30.8 \\
(51.3)\end{array}$ & - & $\begin{array}{l}27.3^{*} \\
(52.0)\end{array}$ & $\begin{array}{c}32.9 \\
(55.8)\end{array}$ & 32 & 54 & 290 & 2 & $\sigma^{7}$ & 28 & *Metatarsus width \\
\hline 2 & - & $\bigcirc$ & $\bigcirc$ & $\begin{array}{l}30.0 \\
(49.5)\end{array}$ & $\begin{array}{c}31.1 \\
(51.9)\end{array}$ & 31.5 & 52 & 275 & 2 & $\sigma^{\top}$ & 27 & Induction of parturition \\
\hline 3 & $\bigcirc$ & $\begin{array}{c}28.5 \\
(46.3)\end{array}$ & $\begin{array}{c}28.8 \\
(47.0)\end{array}$ & $\begin{array}{c}30.0 \\
(49.5)\end{array}$ & $\begin{array}{c}32.1 \\
(54.1)\end{array}$ & 32 & 53 & 280 & 2 & $\sigma^{7}$ & 27 & \\
\hline 4 & - & $\begin{array}{c}27.3 \\
(43.7)\end{array}$ & $\begin{array}{c}27.2 \\
(43.5)\end{array}$ & $\begin{array}{c}26.4 \\
(41.8)\end{array}$ & $\begin{array}{c}28.1 \\
(45.5)\end{array}$ & 28 & 47 & 282 & 1 & 우 & 25 & \\
\hline 5 & - & $\begin{array}{c}24.9 \\
(38.6)\end{array}$ & $\bigcirc$ & $\bigcirc$ & $\begin{array}{c}27.0 \\
(43.1)\end{array}$ & 26.5 & 52 & 286 & 2 & 우 & 24 & \\
\hline 6 & - & $\bigcirc$ & $\begin{array}{c}28.6 \\
(46.5)\end{array}$ & $\begin{array}{l}29.2 \\
(47.8)\end{array}$ & $\bigcirc$ & 31 & 50 & 288 & 2 & 우 & 27.5 & \\
\hline 7 & - & - & - & $\begin{array}{c}27.8 \\
(44.8)\end{array}$ & $\begin{array}{c}29.6 \\
(48.7)\end{array}$ & 29.5 & 45 & 277 & 2 & 우 & 27 & \\
\hline 8 & $\bigcirc$ & $\bigcirc$ & $\begin{array}{c}30.2 \\
(50.0)\end{array}$ & $\begin{array}{c}29.8 \\
(49.1)\end{array}$ & $\begin{array}{c}31.1 \\
(51.9)\end{array}$ & 31.5 & 56 & 289 & 2 & 우 & 27.5 & Induction of parturition \\
\hline 9 & - & - & $\times$ & $\bigcirc$ & $\begin{array}{c}31.2 \\
(52.1)\end{array}$ & 30 & 56 & 282 & 1 & 우 & 25 & Induction of parturtion \\
\hline 10 & - & - & $\begin{array}{c}25.4 \\
(39.6)\end{array}$ & $\begin{array}{c}27.2 \\
(43.5)\end{array}$ & $\begin{array}{c}27.0 \\
(43.1)\end{array}$ & 27.5 & 40 & 276 & 2 & 우 & 25 & \\
\hline 11 & $x$ & $\bigcirc$ & $\bigcirc$ & $\bigcirc$ & $\begin{array}{c}27.2 \\
(43.5)\end{array}$ & 27 & 44 & 287 & 1 & 우 & 22 & \\
\hline \multicolumn{13}{|c|}{ (Nuclear transfer calves derived from somatic cells) } \\
\hline 12 & $\begin{array}{c}29.5 \\
(48.5)\end{array}$ & $\times$ & $\bigcirc$ & $\begin{array}{c}30.9 \\
(51.5)\end{array}$ & $\begin{array}{l}31.9 \\
(53.6)\end{array}$ & 31.5 & 58 & 285 & 2 & 우 & 27 & Induction of parturition \\
\hline 13 & $\begin{array}{c}31.3 \\
(52.3)\end{array}$ & $\bigcirc$ & - & $\begin{array}{c}31.2 \\
(52.1)\end{array}$ & $\begin{array}{c}32.4 \\
(54.7)\end{array}$ & 32 & 55 & 283 & 3 & 우 & 27 & Induction of parturition \\
\hline 14 & - & O & - & $x$ & $\begin{array}{c}31.1 \\
(51.9)\end{array}$ & 30.5 & 54 & 265 & 5 & 우 & 25 & $\begin{array}{l}\text { Dislocation of recipient } \\
\text { Cesarean section, stillbirth }\end{array}$ \\
\hline
\end{tabular}

$\bigcirc$ : The width of the fetal metacarpus or metatarsus could not be measured, but the fetus could be touched.

$x$ : The width of the fetal metacarpus or metatarsus could not be measured, and the fetus could not be touched.

-: No measurement.

fetal body was not palpated at all. As parturition approached, palpation of the fetal body become easier, and it was possible to measure fetal metacarpal width.

During the last week of gestation, fetal metacarpal width was measured with ultrasonography in 13 out of 14 cows, and their mean width of $30.2 \pm 2.2 \mathrm{~mm}$ was fairly similar to the actual width of $30.0 \pm 2.1 \mathrm{~mm}$ after birth. Based on these parameters, the estimated fetal weight was $50.0 \pm 4.7$ $\mathrm{kg}$ before parturition, which was comparable to the actual weight of $51.2 \pm 5.5 \mathrm{~kg}$ after birth. The difference between the width of the metacarpus before and after birth was $0.1-$ $1.2 \mathrm{~mm}$, with some variation. However, estimated fetal weight within the week prior to parturition differed from the actual birth weight, with 7 cases having a difference of less than $3 \mathrm{~kg}, 5$ cases having a difference of $3-5 \mathrm{~kg}$, and one recipient, No.5, having a difference of $8.9 \mathrm{~kg}$.

Eight cows exceeded their fetal metacarpal width of 30 $\mathrm{mm}$ in diameter before parturition. When the time of partu- rition was delayed, there was concern for the risk of dystocia as the offspring would continue to grow to an unmanageable size. Thus, induction of parturition was used in the 5 cows from group A and cesarean section was performed for recipient No. 14, which was not able to stand due to dislocation of the patella.

Parturition was induced in group A $(n=5)$ when the metacarpal width values were above $30 \mathrm{~mm}$, while in group $B(n=2)$, induction was not applied although their width values exceeded the designated threshold. Cows in group $\mathrm{C}$ $(n=5)$ did not have parturition induced because the fetal metacarpal width was estimated less than $30 \mathrm{~mm}$. The metacarpal width $(\mathrm{mm})$, birth weight $(\mathrm{kg})$, gestation period (days), and parturient difficulty of the calves were analyzed for the three subgroups, which were characterized by fetal metacarpal width and induction of parturition within 1 week prior to expected date of parturition (Table 2). 
Table 2. Comparison of the metacarpal width $(\mathrm{mm})$, birth weight $(\mathrm{kg})$, gestation period (days), and parturient difficulty of calves among 3 width-different groups

\begin{tabular}{llllccc}
\hline $\begin{array}{l}\text { Group (number } \\
\text { of cases) }\end{array}$ & $\begin{array}{l}\text { Fetal metacarpal } \\
\text { width }(\mathrm{mm})\end{array}$ & $\begin{array}{l}\text { Induction of } \\
\text { parturition }\end{array}$ & $\begin{array}{l}\text { Metacarpal } \\
\text { width }(\mathrm{mm})\end{array}$ & $\begin{array}{c}\text { Birth weight } \\
(\mathrm{kg})\end{array}$ & $\begin{array}{c}\text { Gestation } \\
\text { period (days) }\end{array}$ & $\begin{array}{l}\text { Parturient } \\
\text { difficulty }\end{array}$ \\
\hline A $(\mathrm{n}=5)$ & $\geq 30 \mathrm{~mm}$ & Treatment & $31.3 \pm 0.76^{\mathrm{a}}$ & $55.4 \pm 2.2^{\mathrm{a}}$ & $282.8 \pm 5.1^{\mathrm{a}}$ & $2.0 \pm 0.7^{\mathrm{a}}$ \\
$\mathrm{B}(\mathrm{n}=2)$ & $\geq 30 \mathrm{~mm}$ & No treatment & $32.0 \pm 0^{\mathrm{a}}$ & $53.5 \pm 0.7^{\mathrm{ab}}$ & $285.0 \pm 7.1^{\mathrm{a}}$ & $2.0 \pm 0^{\mathrm{a}}$ \\
$\mathrm{C}(\mathrm{n}=5)$ & $<30 \mathrm{~mm}$ & No treatment & $27.7 \pm 1.15^{\mathrm{b}}$ & $45.6 \pm 4.4^{\mathrm{bc}}$ & $281.6 \pm 5.0^{\mathrm{a}}$ & $1.6 \pm 0.5^{\mathrm{a}}$ \\
\hline
\end{tabular}

Data are expressed as means \pm standard deviation. The different superscripts indicate significant differences $(\mathrm{p}<0.05)$. A Cows in which induction of parturition was carried out due to metacarpal width values greater than $30 \mathrm{~mm}$. B: Cows allowed to have natural parturition even though metacarpal width values exceeded $30 \mathrm{~mm}$. C: Cows with metacarpal width values less than $30 \mathrm{~mm}$ and to which no induction of parturition was attempted.

\section{DISCUSSION}

Currently, there are several publications reporting on the estimation of fetal weight. It has been shown that the estrone and estradiol concentrations in maternal plasma are associated with fetal growth $[5,6]$ and the number of fetuses [11] during pregnancy in the cow. A relationships has been shown between the estrone and estradiol concentrations and the birth weight during pregnancy of sheep [2]. Moreover, it has been reported that the bovine pregnancy associated glycoprotein (bPAG) concentration are correlated with birth weight during pregnancy of the cow [8], placental steroids and bPAG are correlated with birth weight. However, there has been no method to accurately predict fetal weight.

Almost all fetuses (13 out of 14) measured in this study were in cephalic presentation, which is in contrast with the high tendency of posterior presentations for nuclear transfer fetuses previously reported by our research group [9]. Only one cow (Recipient No.1) had a fetus in posterior presentation within the 8-14 day period prior to parturition. All other observations were cephalic presentations. There exists a possibility that the fetus might have changed the presentation halfway towards a posterior presentation. Even though we were not able to touch a fetus in some cases, probably due to it being in an unreachable location within the large uterine cavity, it might have been possible to stimulate changes in the fetal behavior and position during rectal palpation in the last week of gestation. Against these fetal changes, constant measurement of the fetal metacarpal width would be advisable. It is important to accurately distinguish the metacarpus of the fore-limbs from the metatarsus of the pelvic limbs. If the metatarsal width was erroneously measured as the metacarpal width, there is a risk of underestimating fetal weight because the metatarsal width is anatomically smaller than the metacarpal width.

The fetal metacarpal width measured with ultrasonic diagnostic equipment and the estimated fetal weight within 1 week prior to parturition were closely approximated to the calf's metacarpal width and the body weight immediately after birth. Therefore, we believe that the birth weight can be estimated within 1 week prior to parturition. Each measurement difference between the calves' metacarpal width and fetal metacarpal width within one week prior to parturition was only a slight variation. Although fetal weight was successfully estimated before parturition based on the metacarpal width measured with ultrasonography, there was some variation from actual values. In recipient No.5, actual weight after birth was $52 \mathrm{~kg}$ compared to an estimated weight of $43.1 \mathrm{~kg}$ one prior to parturition. In the future, it will be necessary to examine the frequency of occurrence of similar extreme cases. We had previously suggested that the weight at birth could be assessed even earlier than the 8-day period prior to the expected date of parturition using the prepartum metacarpal width relationship in Holstein calves. These results suggest that the ultrasonographic approach to assess pre-partum fetal metacarpal width is reliable to predict fetal weight of Holstein calves. As a result, when the presence of large offspring syndrome is predicted by this method, induction of parturition before the scheduled date could prevent dystocia. Moreover, the estimate of fetal weight by reducing the number of measurements is being considered as a future examination subject.

Although the gestation period of A group was 2.2 days shorter than that of B group, the birth weight of calves in A group was $1.9 \mathrm{~kg}$ heavier than that of $\mathrm{B}$ group. If induction of parturition was not been carried out in group A the gestation periods would have been extended, birth weights would have increased, and a high possibility of complicated parturitions could have occurred. The average birth weight of group $\mathrm{C}$ was $9.8 \mathrm{~kg}$ lighter than that of group $\mathrm{A}$, and in the same way, the average metacarpal width was less than 30 $\mathrm{mm}$. Thus, the probability for the occurrence of dystocia was low. Therefore, parturition was allowed to occur naturally and no inductive treatment was conducted. No significant difference was recognized in regard to the parturient difficulty.

Dystocia occurs through the interrelation of fetal causes, such as birth weight, and maternal causes, such as the size of the pelvis [4]. Every $1 \mathrm{~kg}$ increase in birth weight augments the occurrence of dystocia by $2.4 \%$ on average [4]. Birth weight has been shown as an important factor of dystocia, and therefore estimation of fetal weight before parturition could be a warning of the risk of dystocia. In regard to fetal causes, dystocia is caused not only by the fetal size, but also by fetal displacement and malformation [4]. Neither fetal displacement nor fetal malformation occured in this study, but we should consider, according to these factors, the possibility that dystocia can be caused even if the fetal size is 
normal. Holstein cows were used as recipients for embryo transfer in this study because we believed that their broad pelvis would facilitate a reduction in parturient difficulty compared to heifers. At our farm, Holstein heifers were not used as recipients for this study. However, it is important to note that the size of the pelvis should be measured with a measurement apparatus, such as a bovine pelvic meter [4], for prevention of dystocia by maternal causes, and cows with a remarkably narrow pelvis should not be used for Holstein calf breeding.

Therefore, pre-partum measurement of the width of the metacarpus or metatarsus with ultrasonography would lower the risk of dystocia originating from large offspring, and contribute to minimizing stillbirth or death losses and increasing the survival rate after birth. Even though oversize of nuclear transfer calves cannot be prevented at present, this method could eliminate the occurrence of dystocia.

The present report shows the advantage of ultrasonic diagnostic equipment for the prediction of fetal birth weight prior to parturition for the purpose of predicting Large Offspring Syndrome in nuclear transfer fetuses. Further analysis is necessary to apply this technique to the fetuses produced by artificial insemination or conventional embryo transfer.

ACKNOWLEDGMENTS. This study was supported by the Japanese Research Association for Animal Embryo Transfer Technology and was subsidized by the Ministry of Agriculture, Forestry and Fisheries of Japan in 2000.

\section{REFERENCES}

1. Brink, M.F., Bishop, M.D. and Pieper, F.R. 2000. Developing efficient strategies for the generation of transgenic cattle which produce biopharmaceuticals in milk. Theriogenology 53: 139148.

2. Caton, D., Kalra, P.S. and Wilcox, J. 1983. Relationships between maternal hormones and weight of newborn sheep. Am. J. Physiol. 244: R31-R35.
3. Garry, F.B., Adams, R., McCann, J.P. and Odde, K.G. 1996. Postnatal characteristics of calves produced by nuclear transfer cloning. Theriogenology 45: 141-152.

4. Nakao, T. 1995. Dystocia. pp. 370-387 In: Textbook of Theriogenology (Mori, J., Kanagawa, H. and Hamana, K. eds.), Buneido Publishing Co., Ltd., Tokyo (in Japanese).

5. Ogata, Y., Takahashi, K., Abe, H., Misawa, T., Katou, T., Sakai, J., Ohsaki, K., Nanpo, Y., Nakada, K. and Nakao, T. 1996. Relationship between serum concentrations of placental steroids in dams and the birth weight and viability of newborns in Japanese Black cattle. J. Reprod. Dev. 42: j85-j89 (in Japanese).

6. Patel, O.V., Hirako, M., Takahashi, T., Sasaki, N. and Domeki, I. 1995. Sex steroid levels throughout gestation in cows carrying normal and malformed fetuses. J. Vet. Med. Sci. 57: 659663.

7. Prather, R.S., Barnes, F.L., Sims, M.M., Robl, J.M., Eyestone, W.H. and First, N.L. 1987. Nuclear transplantation in the bovine embryo: assessment of donor nuclei and recipient oocyte. Biol. Reprod. 37: 859-866.

8. Schmidt, M., Greve, T., Avery, B., Beckers, J.F., Sulon, J. and Hansen, H.B. 1996. Pregnancies, calves and calf viability after transfer of in vitro produced bovine embryos. Theriogenology 46: $527-539$.

9. Takahashi, M., Ueki, A., Kawahata, K. and Goto, T. 2000. Characterization and parturient condition of Holstein calves produced by nuclear transfer embryo. J. Jpn. Vet. Med. Assoc. 53: 387-390 (in Japanese).

10. Takahashi, M., Ueki, A., Kawahata, K. and Goto, T. 2001. Relationships between the width of metacarpus or metatarsus and the birth weight in Holstein calves. J. Reprod. Dev. 47: 105-108.

11. Takahashi, T., Hirako, M., Takahashi, H., Patel, O.V., Takenouchi, N. and Domeki, I. 1997. Maternal plasma estrone sulfate profile during pregnancy in the cow; Comparison between singleton and twin pregnancies. J. Vet. Med. Sci. 59: 287-288.

12. Willadsen, S.M., Janzen, R.E., McAlister, R.J., Shea, B.F., Hamilton, G. and McDermand, D. 1991. The viability of late morulae and blastocysts produced by nuclear transplantation in cattle. Theriogenology 35: 161-170.

13. Yang, X. and Anderson, G.B. 1992. Micromanipulation of mammalian embryos: principles, progress and future possibilities. Theriogenology 38: 315-335. 